\title{
Classical conditioning of the rabbit's nictitating membrane response to CS compounds: Effects of prior single-stimulus conditioning
}

\author{
BERNARD G. SCHREURS and I. GORMEZANO \\ University of Iowa, Iowa City, Iowa 52242
}

\begin{abstract}
Two experiments were conducted to determine the effects of prior single-stimulus training on classical conditioning to a compound and its components and subsequent component extinction of the rabbit's nictitating membrane response. Experiments 1 and 2 found that prior singlestimulus training interfered with acquisition of responding to a second stimulus during compound conditioning and retarded responding to the second stimulus during extinction. Moreover, Experiment 2 revealed that the interference effects of prior single-stimulus training on response acquisition to a second stimulus were attenuated by the addition of concurrent training trials to the second stimulus. The results are discussed in terms of theories of stimulus selection.
\end{abstract}

The purpose of the present experiments was to determine whether conditioning of the rabbit's nictitating membrane response to a compound and its components would be affected by prior component training. In particular, the present experiments manipulated the strength of responding to component CSs and determined the effects of these manipulations on the acquisition of conditioned responses (CRs) to the compound and components in order to examine how stimuli interact.

A great deal of interest has centered on negative stimulus interactions, such as blocking (e.g., Kamin, 1968) and overshadowing (e.g., Mackintosh, 1965), in which CR acquisition to an otherwise effective stimulus is retarded, if not prevented, as result of the subject's being trained with another previously trained or more intense stimulus. In particular, blocking has been extensively studied (e.g., Dickinson, Hall, \& Mackintosh, 1976; Gaioni, 1982; Johnson, 1970; Kamin, 1968, 1969; Kehoe, Schreurs, \& Amodei, 1981; Mackintosh, Dickinson, \& Cotton, 1980; Marchant \& Moore, 1973; Miles, 1970; Tennant \& Bitterman, 1975; Vom Saal \& Jenkins, 1970) because the contiguity of the "blocked" stimulus and the reinforcer has posed a strong challenge to the sufficiency of a CS-UCS contiguity account of conditioning (Kamin, 1968). In order to account for blocking and its challenge to CS-UCS contiguity, a number of theories contend that CS-UCS contiguity is necessary for conditioning but that the effect of contiguity can be attenuated in a compound stimulus (e.g., Mackintosh, 1975; Mackintosh, Dickinson, \& Cotton, 1980; Rescorla \& Wagner, 1972; Sutherland \& Mackintosh, 1971). Although these theories differ in

This research was supported by National Science Foundation Grant BNS 80-05907. many details, they all assume that stimuli compete either for "associative strength" (Mackintosh, 1975; Rescorla \& Wagner, 1972) or "attention" (Sutherland \& Mackintosh, 1971) and, accordingly, that blocking occurs because a previously trained stimulus has already acquired all the available associative strength or attention, to the exclusion of the added stimulus. In a theoretical context, blocking has been used to refer to the purported interference with an acquisition process during compound conditioning (Gaioni, 1982; Kamin, 1968, 1969; Mackintosh, 1975; Tennant \& Bitterman, 1975), but operationally, all of these investigators have measured blocking during a limited number of extinction trials. Indeed, despite the extensive number of investigations of blocking, there is only one report, to our knowledge, in which component responding was assessed during the course of the purported interference with the acquisition process to components (Kehoe et al., 1981). Specifically, Kehoe et al. (1981) found, as determined on test trials during acquisition training to compounds, that while blocking occurred, it was incomplete and the level of responding to the "blocked" stimulus increased over the course of compound conditioning. The present experiments are intended to further examine and expand upon the Kehoe et al. (1981) findings by employing test trials during compound conditioning to assess the effects on CR acquisition of manipulating component pretraining to one (Experiment 1) and then both (Experiment 2) components of the compound.

\section{EXPERIMENT 1}

The present experiment was designed to assess the effects of single-stimulus pretraining (360 vs. 0 CS-UCS 
pairings) on the acquisition of CRs to a compound and its components. In so doing, the present experiment provides the opportunity to directly observe the effects of extensive prior training with one component of a to-beformed compound on the subsequent acquisition of responding to a second stimulus during compound conditioning; therefore, the study permits an assessment of theoretical accounts of blocking (e.g., Kamin, 1969; Mackintosh, 1975; Rescorla \& Wagner, 1972; Sutherland \& Mackintosh, 1971).

\section{Method}

Subjects. The subjects were 36 naive male and female albino rabbits (Orytolagus cuniculus), each 60-80 days old and weighing about $2.0 \mathrm{~kg}$ on arrival at the laboratory.

Apparatus. The conditioning chambers, apparatus, and recording techniques have been described by Coleman and Gormezano (1971). The auditory CS was a $300-\mathrm{msec}, 1,000-\mathrm{Hz}, 82-\mathrm{dB}$ (re $20 \mathrm{microN} / \mathrm{m}$ ) tone superimposed on a $70-\mathrm{dB}$ background provided by chamber ventilating fans. The visual CS was a $300-\mathrm{msec}, 10-\mathrm{Hz}$, stroboscopic light flash, resulting in an increase in chamber illumination of $8.01 \mathrm{x}$. The UCS was a $50 \mathrm{msec}, 3 \mathrm{~mA}$, $60-\mathrm{Hz}$ shock delivered to the subject's orbital region through two stainless steel Autoclip sutures positioned $15 \mathrm{~mm}$ apart and $15 \mathrm{~mm}$ posterior to the dorsal canthus of the right eye. The CSUCS interval was $400 \mathrm{msec}$.

Procedure. Prior to acquisition training, all subjects received 1 day of preparation, followed by a 1-day recovery period and 1 day of adaptation. On the preparation day, a $2-m m$-diam loop of 4-0 Ethicon monofilament was sutured into the right nictitating membrane and the surrounding hair was removed. On the adaptation day, the UCS electrodes were implanted and the restrained subjects were placed in the conditioning chambers with the recording apparatus attached for a period of time equivalent to the length of the subsequent conditioning sessions. Twelve subjects were randomly assigned to each of the three groups: a light pretraining group (Group L6), a tone pretraining group (Group T6), and a control group that sat in the restrainers during the first stage (Group S6).

Stage 1 pretraining consisted of six daily sessions in which Groups L6 and T6 received 60 reinforced trials to light and tone, respectively. Group S6 experienced daily sessions of restraint in the conditioning chambers for a duration equal to that of the experimental groups. During Stage 2 compound conditioning, all groups received a total of 60 trials for each of six daily sessions. Each session involved 54 reinforced presentations of a simultaneous compound of tone and light and 6 nonreinforced test trials consisting of 2 test trials to each component and the compound. Each test trial was separated by nine reinforced compound trials, with the restrictions that (1) the first test trial for each of the six sessions was to be different from that of the previous session and (2) no adjacent test trial within the session was to contain the same stimulus. Stage 3 consisted of six daily extinction sessions, each involving random presentations of 30 tone-alone and 30 light-alone trials, with the restriction that there be no more than two consecutive presentations of the same stimulus within the session. Throughout the three stages of the experiment, a CR was defined as a membrane extension of $.5 \mathrm{~mm}$ or more, occurring within $400 \mathrm{msec}$ after CS onset.

\section{Results}

During Stage 1 pretaining (figure not shown), responding in Groups L6 and T6 negatively accelerated to the same high asymptotic level of $98 \% \mathrm{CRs}$, whereas responding in Group S6 during the same observation intervals
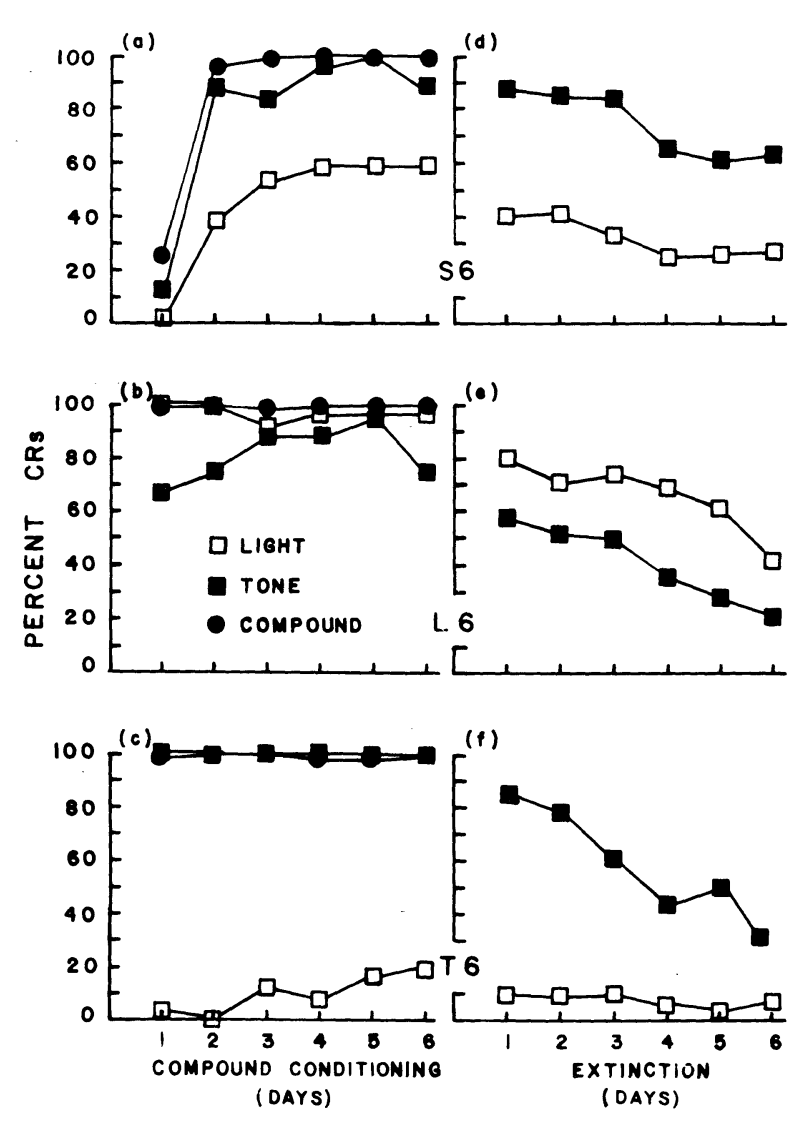

Figure 1. Panels a, b, and c present mean percentage of CRs in 1-day blocks for each group on nonreinforced test trials to tone, light, and compound during Stage 2 compound conditioning. Panels $d, e$, and $f$ present mean percentage CRs for nonreinforced tone and light trials during extinction.

revealed a base rate level of responding that did not exceed $2 \%$. As seen in Panels a, b, and c of Figure 1, during Stage 2 compound conditioning, CR acquisition to the compound was rapid and reached an asymptotic level of $100 \%$, whereas the level of Stage 2 CR acquisition and Stage 3 extinction (Panels $d, e$, and $f$ ) to the components was a function of prior training history. Specifically, analyses of variance indicated significant differences in component response levels as a function of type of pretraining during both compound conditioning $[F(4,66)=68.37, \mathrm{p}<.01]$ and extinction $[F(2,33)=39.43, p<.01]$. The difference in levels of responding between groups were localized by Scheffé post hoc comparisons (Scheffé, 1953) to higher CR acquisition and less extinction to light in Group S6 than in Group T6 [Panels a and c, critical difference (CD) $=.37$, $\mathrm{p}<.01$; Panels $\mathrm{d}$ and $\mathrm{f}, \mathrm{CD}=.26, \mathrm{p}<.01]$, and less extinction to tone in Group S6 than in Group L6 (Panels $\mathrm{d}$ and $\mathrm{e}, \mathrm{CD}=.33, \mathrm{p}<.01)$. Accordingly, tone was capable of blocking CR acquisition to light as directly assessed during compound conditioning and indirectly 
assessed during extinction. Although the high level of responding to tone indicated the failure of light to block tone $\mathrm{CR}$ acquisition, there was indirect evidence of blocking during extinction as the response levels to tone became less than asymptotic. Moreover, when there was no pretraining (Group S6), the level of responding to tone during compound conditioning and extinction was higher than the level of responding to light (Panel a, $\mathrm{CD}=.32, \mathrm{p}<.01$; Panel $\mathrm{d}, \mathrm{CD}=.42, \mathrm{p}<.01$ ), suggesting an overshadowing effect of tone on light.

\section{EXPERIMENT 2}

The purpose of Experiment 2 was to determine whether conditioning to a compound and its components could be affected by prior single-stimulus training to both components. Accordingly, in a three-stage design similar to that employed in Experiment 1, the level of light training was manipulated by presenting interpolated light-shock pairings $(0,60$, and $180 \mathrm{CS}$-UCS pairings) during the course of tone training (360 CS-UCS pairings) in Stage 1, whereas the tone and light stimuli were conditioned in compound during Stage 2 and extinguished as separate components in Stage 3.

\section{Method}

Subjects. The subjects were 24 naive male and female albino rabbits, $60-80$ days old and weighing approximately $2.0 \mathrm{~kg}$ upon arrival at the laboratory.

Procedure. Unless otherwise specified, the apparatus, general procedure, and response specification of Experiment 2 were the same as those described in Experiment 1. Eight rabbits were randomly assigned to each of three groups, comprising a tonealone control group (Group T0L), a tone plus 10 light trials group (Group T10L), and a tone plus 30 light trials group (Group T30L). In Stage 1 pretraining, all subjects received six daily session of 60 reinforced tone trials, with a mean intertrial interval of $60 \mathrm{sec}$. Groups T10L and T30L received 10 and 30 reinforced light trials, respectively, interpolated among their 60 reinforced tone trials. In the case of Group T10L, the reinforced light trials occurred after every 60 th tone trial;Group T30L received a reinforced light after every 2 nd tone trial. Stage 2 compound conditioning and Stage 3 extinction were identical to those employed in Experiment 1.

\section{Results}

During Stage 1 (figure not shown) the level of responding to the tone in all three groups acquired asymptotic levels of approximately $90 \%$ CRs. On the other hand, the $50 \%$ and $70 \%$ levels of responding to light revealed in Groups T10L and T30L, respectively, although significantly lower than responding to tone, were not significantly different from each other. As seen in Panels $a, b$, and $c$ of Figure 2, during Stage 2 compound conditioning, CR acquisition to the compound was rapid and reached levels of $90 \%-100 \%$. While the level of Stage $2 \mathrm{CR}$ acquisition and Stage 3 extinction (Panels $\mathrm{d}, \mathrm{e}$, and $\mathrm{f}$ ) to the tone did not differ between groups, CR acquisition and extinction to the light were functions of prior training history. Specifically, analyses
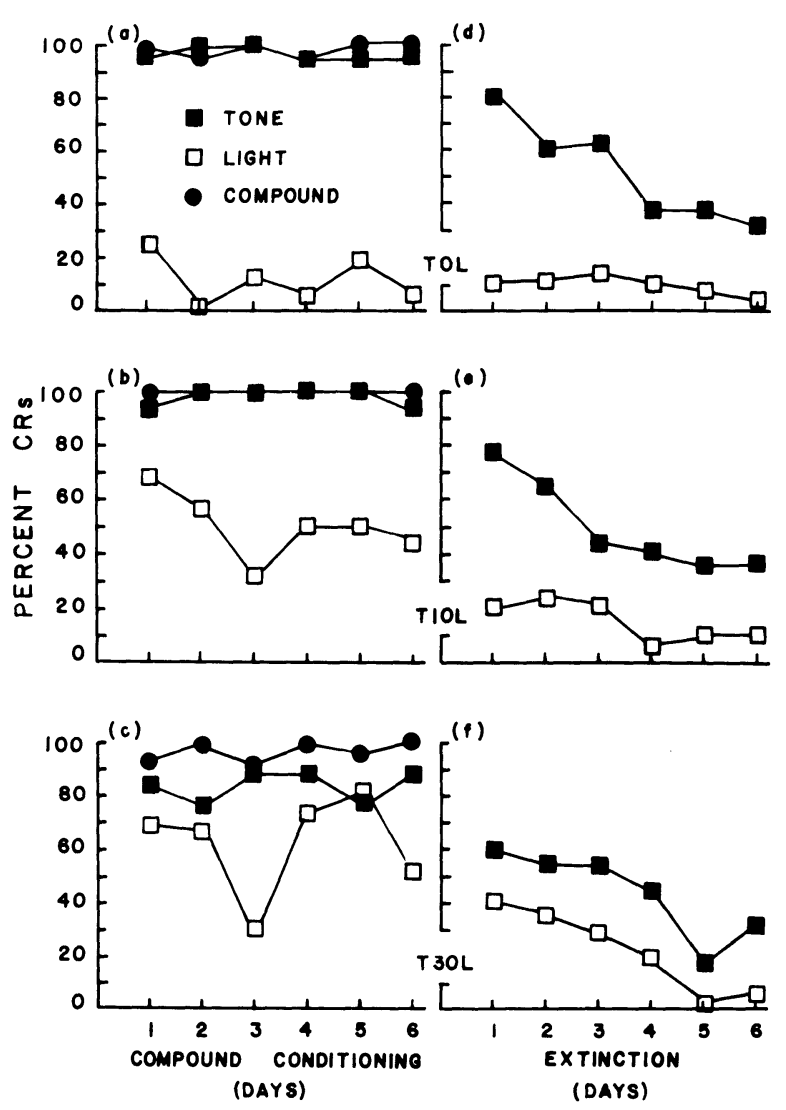

Figure 2. Panels a, b, and c present mean percentage of CRs in 1-day blocks for each group on nonreinforced test trials to tone, light, and compound during Stage 2 compound conditioning. Panels $d, e$, and $f$ present mean percentage CRs for nonreinforced tone and light trials during extinction.

of variance indicated significant differences in component response levels as a function of type of pretraining during compound conditioning $[\mathrm{F}(4,42)=13.15$, $\mathrm{p}<.01]$, as well as a function of type of pretraining and days during extinction $[F(5,105)=p<.01]$. The differences in response levels during Stage 2 compound conditioning were localized by Scheffé post hoc comparisons to higher CR acquisition to light in groups that received light pretraining (T10L and $\mathrm{T} 30 \mathrm{~L}$ ) than in the group that did not (TOL) (Panels a and b, CD = .32, p <.01; Panels $\mathrm{a}$ and $\mathrm{c}, \mathrm{CD}=.50, \mathrm{p}<.01)$. Accordingly, the interactive ("blocking") effects of tone pretraining on subsequent $\mathrm{CR}$ acquisition to light can be ameliorated by concurrent light pretraining. The differences in responding during Stage 3 extinction were localized to differences in the level of light responding. Specifically, Scheffé posthoc comparisons indicated that while converging to the same low level, extinction to light was more complete for groups receiving little (T10L) or no (TOL) light pretraining than for the group receiving extensive light pretraining (Panels $d$ and $f, C D=1.8$, $\mathrm{p}<.01 ;$ Panels e and $\mathrm{f}, \mathrm{CD}=1.43, \mathrm{p}<.01)$. 


\section{DISCUSSION}

Experiments 1 and 2 showed that prior single-stimulus training interfered with, but did not completely prevent, subsequent acquisition of CRs to a second stimulus during compound conditioning. Moreover, Experiment 2 revealed that the interference effects of prior single-stimulus training on response acquisition to a second stimulus were attenuated by the addition of concurrent training trials to that second stimulus. Finally, it was found that with no prior single-stimulus training, differential levels of responding to the components of a compound during compound conditioning and component extinction provided evidence of tone CSs overshadowing light CSs.

Although theoretical accounts of blocking and overshadowing have involved the assertion of processes purported to be operating during acquisition, empirical tests have generally been based on an assessment of responding in extinction (e.g., Rescorla \& Wagner, 1972; Sutherland \& Mackintosh, 1971). Hence, the assessment of the interference phenomena has occurred after the purported mechanisms responsible for blocking and overshadowing (e.g., competition; see Rescorla \& Wagner, 1972) have had the opportunity to be operative. Nevertheless, the blocking and overshadowing of components presently observed during the course of compound conditioning are consistent with theoretical accounts of stimulus interactions. Furthermore, the extensive amount of component pretraining in producing asymptotic levels of 90\%-98\% CRs might have been expected to result in the component's acquiring almost all of the available associative strength or attention, and thus, to preclude the availability of associative strength (Rescorla \& Wagner, 1972) or attention (Sutherland \& Mackintosh, 1971) to the second stimulus. However, the present findings indicate that blocking was far from complete, with components attaining levels from $20 \%$ to $85 \%$ CRs, depending upon modality, and, furthermore, that these levels of responding were generally characterized by orderly acquisition functions over the course of compound conditioning. Of course, theoretical accounts of blocking could appeal to the learningperformance distinction and contend that the discrepancy merely reflects the failure of the performance measure (of near-100\% CRs in pretraining) to reflect the ceiling for strength of learning.

\section{REFERENCES}

Coleman, S. R., \& Gormezano, I. Classical conditioning of the rabbit's (Orytolagus cuniculus) nictitating membrane response under symmetrical CS-US interval shifts. Journal of Comparative and Physiological Psychology, 1971, 77, 447-455.
Dickinson, A., Hall, G., \& Mackintosh, N. J. Surprise and the attenuation of blocking. Journal of Experimental Psychology: Animal Behavior Processes, 1976, 2, 313-322.

GaIONI, S. J. Blocking and nonsimultaneous compounds: Comparison of responding during compound conditioning and testing. Pavlovian Journal of Biological Science, 1982, 17, 16-29.

Johnson, D. F. Determiners of selective stimulus control in the pigeon. Journal of Comparative and Physiological Psychology, 1970, 70, 298-307.

KAMIN, L. J. "Attention-like" processes in classical conditioning. In M. R. Jones (Ed.), Miami symposium on the prediction of aversive behavior: Aversive stimulation. Miami: University of Miami Press, 1968.

Kamin, L. J. Predictability, surprise, attention, and conditioning. In B. A. Campbell \& R. M. Church (Eds.), Punishment and aversive behavior. New York: Appleton-Century-Crofts, 1969.

Kenoe, E. J., Schreurs, B. G., \& Amode i, N. Blocking acquisition of the rabbit's nictitating membrane response to serial conditioning stimuli. Learning and Motivation, 1981, 12, 92-108.

Mackintosh, N. J. Selective attention in animal discrimination learning. Psychological Bulletin, 1965, 64, 124-150.

Mackintosh, N. J. A theory of attention: Variations in the associability of stimuli with reinforcement. Psychological Review, 1975, 82, 276-298.

Mackintosh, N. J., Dickinson, A., \& Cotron, M. M. Surprise and blocking: Effects of the number of compound trials. Animal Learning \& Behavior, 1980, 8, 387-391.

Marchant, H. G., \& Moore, J. W. Blocking of the rabbit's conditioned nictitating membrane response in Kamin's two-stage paradigm. Journal of Experimental Psychology, 1973, 101, 155158.

Miles, C. G. Blocking the acquisition of control by an auditory stimulus with pretraining on brightness. Psychonomic Science, $1970,19,133-134$.

Rescorla, R. A., \& Wagner, A. R. A theory of Pavlovian conditioning: Variations in the effectiveness of reinforcement and nonreinforcement. In A. H. Black \& W. F. Prokasy (Eds.), Classical conditioning II: Current research and theory. New York: Appleton-Century-Crofts, 1972.

Scheffe, H. A method for judging all possible contrasts in the analysis of variance. Biometrika, 1953, 40, 87-104.

Sutherland, N. S., \& Mackintosh, N. J. Mechanisms of animal discrimination learning. New York: Academic Press, 1971.

Vom SAAL, W., \& Jenkins, H. M. Blocking the development of stimulus control. Learning and Motivation, 1970, 1, 52-64.

(Received for publication May 1, 1982.) 